\title{
Editorial: Diabetes and its association with hepatocellular carcinoma in chronic hepatitis B
}

\author{
Monica Konerman, MD MSc ${ }^{1}$ and Rohit Loomba, MD, MHSc ${ }^{2,3,4}$ \\ ${ }^{1}$ Division of Gastroenterology and Hepatology, Department of Medicine, University of Michigan, \\ University of California at San Diego, La Jolla, CA 92093-0063 \\ ${ }^{2}$ NAFLD Translational Research Unit, University of California at San Diego, La Jolla, CA \\ 92093-0063
}

3Division of Gastroenterology, Department of Medicine, University of California at San Diego, La Jolla, CA 92093-0063

${ }^{4}$ Division of Epidemiology, Department of Family and Preventive Medicine, University of California at San Diego, La Jolla, CA 92093-0063

\section{Keywords}

Viral hepatitis; fatty liver; NASH; diabetes mellitus; liver cancer; cirrhosis

\begin{abstract}
The impact of metabolic syndrome and its complications, namely hepatic steatosis and diabetes, have appropriately become focal points of investigation within hepatology in the setting of the evolving obesity epidemic. Although there is a large body of research that has demonstrated an increased risk of hepatocellular carcinoma (HCC) in patients with diabetes, the specific disease characteristics that modify this relationship require further investigation. (1) This is particularly the case in patients with viral hepatitis, where studies have produced conflicting data in terms of the independent association of metabolic risk factors with HCC. $(1-4)$
\end{abstract}

In a recent issue, Fu et al provide further data to support the observation of increased risk of HCC for diabetic patients with CHB.(5) Using the Taiwanese National Health Insurance Research Database, they included a random sample of 2099 patients with CHB with newonset diabetes and 2080 age, gender, and inception-point matched non-diabetic patients. After adjusting for possible contributing factors, diabetes was an independent predictor for HCC with a hazard ratio of 1.798 .

This study has several strengths including a large sample-size, length of longitudinal followup, and accounting for multiple potential confounders for competing risk for developing HCC. Several unaddressed questions remain however, particularly those stemming from the lack of histology to address possible concomitant steatohepatitis. It is well known that

Corresponding Author: Rohit Loomba, MD, MHSc, Division of Gastroenterology and Epidemiology, University of California at San Diego School of Medicine, 9500 Gilman Drive, La Jolla, CA 92093-0063, Ph: 858-534-2624, Fax: 858-534-3338, roloomba@ucsd.edu Website : fattyliver.ucsd.edu. 
diabetes is an independent risk factor and driver of steatohepatitis, and untreated steatohepatitis, along with other metabolic dysregulations associated with diabetes, have been shown to increase the risk of HCC in the setting of hepatitis B infection. $(6,7)$ Additionally, further detail regarding duration of diabetes and control of diabetes on the risk of HCC should also be evaluated. $(2,3,8,9)$ Lastly, the impact of anti-diabetic regimen should be assessed as data has suggested decreased risk of HCC and liver related mortality in patients on metformin. $(8,10)$ In this study only $39 \%$ of diabetics were on treatment and the effect of diabetic treatment agents on HCC risk was not assessed.

Overall this study demonstrates the importance of addressing modifiable metabolic risk factors in patients with CHB. Lifestyle interventions to prevent obesity, diabetes and other features of the metabolic syndrome should be emphasized in the care of patients with CHB. Further studies are needed to clarify the attributable risk of HCC in diabetics (such as duration and severity of steatohepatitis), as well as optimal treatment of steatohepatitis, in order to minimize the risk of incident $\mathrm{HCC}$ in CHB.

\section{Acknowledgments}

Funding support: RL is supported in part by the American Gastroenterological Association (AGA) Foundation Sucampo - ASP Designated Research Award in Geriatric Gastroenterology and by a T. Franklin Williams Scholarship Award; Funding provided by: Atlantic Philanthropies, Inc, the John A. Hartford Foundation, the Association of Specialty Professors, and the American Gastroenterological Association and grant K23-DK090303. MK is supported by the National Institutes of Health T32DK062708 training grant.

\section{References}

1. El-Serag HB, Hampel H, Javadi F. The association between diabetes and hepatocellular carcinoma: a systematic review of epidemiologic evidence. Clin Gastroenterol Hepatol. 2006; 4:369-380. [PubMed: 16527702]

2. Gao C, Fang L, Zhao HC, Li JT, Yao SK. Potential role of diabetes mellitus in the progression of cirrhosis to hepatocellular carcinoma: a cross-sectional case-control study from Chinese patients with HBV infection. Hepatobiliary Pancreat Dis Int. 2013; 12:385-393. [PubMed: 23924496]

3. Koh WP, Wang R, Jin A, Yu MC, Yuan JM. Diabetes mellitus and risk of hepatocellular carcinoma: findings from the Singapore Chinese Health Study. Br J Cancer. 2013; 108:1182-1188. [PubMed: 23370206]

4. Wang CS, Yao WJ, Chang TT, Wang ST, Chou P. The impact of type 2 diabetes on the development of hepatocellular carcinoma in different viral hepatitis statuses. Cancer Epidemiol Biomarkers Prev. 2009; 18:2054-2060. [PubMed: 19549812]

5. Fu Y-WH S-C, Wang T-C, Hu J-T, Chen S-S, Yang S-S. Increased risk of hepatocellular carcinoma in chronic hepatitis B patients with new onset diabetes: a nationwide cohort study. Alimentary Pharmacology and Therapeutics. 2015

6. Chen CL, Yang HI, Yang WS, Liu CJ, Chen PJ, You SL, Wang LY, et al. Metabolic factors and risk of hepatocellular carcinoma by chronic hepatitis B/C infection: a follow-up study in Taiwan. Gastroenterology. 2008; 135:111-121. [PubMed: 18505690]

7. Loomba R, Yang HI, Su J, Brenner D, Barrett-Connor E, Iloeje U, Chen CJ. Synergism between obesity and alcohol in increasing the risk of hepatocellular carcinoma: a prospective cohort study. Am J Epidemiol. 2013; 177:333-342. [PubMed: 23355498]

8. Donadon V, Balbi M, Valent F, Avogaro A. Glycated hemoglobin and antidiabetic strategies as risk factors for hepatocellular carcinoma. World J Gastroenterol. 2010; 16:3025-3032. [PubMed: 20572306] 
9. Yang X, Wang Y, Luk AO, So WY, Ma RC, Kong AP, Xu G, et al. Enhancers and attenuators of risk associations of chronic hepatitis B virus infection with hepatocellular carcinoma in type 2 diabetes. Endocr Relat Cancer. 2013; 20:161-171. [PubMed: 23250907]

10. Loomba R. Rationale for conducting a randomized trial to examine the efficacy of metformin in improving survival in cirrhosis: pleiotropic effects hypothesis. Hepatology. 2014; 60:1818-1822. [PubMed: 25043205] 